\title{
FUNDEB E A VALORIZAÇÃO DA EDUCAÇÃO PÚBLICA: LIMITES NA REMUNERAÇÃO DO MAGISTÉRIO DE SÃO LUÍS - MA
}

\author{
Regina Sheila Bordalo Martins ${ }^{1}$ \\ Maria José Pires Barros Cardozo
}

\section{RESUMO}

O artigo aborda a política de fundos no contexto da Reforma do Estado Capitalista, desvelando as concepções de financiamento educacional e a consequente vinculação constitucional dos recursos destinados à educação pública. A análise apresenta as limitações dessa política de fundos, considerando o Fundeb,diante dos ínfimos recursos destinados para a educação pública.Apresenta a aplicação dos recursos do Fundeb no período de 2007-2013, analisando os impactos na valorização do Magistério Público da rede municipal de São Luís - MA, principalmente no que concerne à remuneração salarial. Conclui-se que apesar do aumento dos recursos destinados à educação pública municipal pelo Fundeb, observou-se a diminuição do percentual aplicado com a remuneração dos professores e a consequente desvalorização profissional do Magistério Público.

Palavras-chave: Fundeb; Financiamento da Educação; Valorização do Magistério.

\section{FUNDEB AND THE VALORIZATION OF PUBLIC EDUCATION: LIMITS ON THE COMPENSATION OF SÃO LUÍS TEACHING PROFESSIONALS}

\begin{abstract}
The article discusses the politics of funds in the context of the capitalist state reform, unveiling the educational financing concepts and the consequent Constitutional binding of resources for public education. The analysis shows the limitations of funds policy, considering the Fundeb, given the meager resources allocated to public education. It presents the application of Fundeb resources in the 2007-2013 period, analyzing the impact on the valuation of the Public Magisterium of the city of São Luís - MA, especially regarding the wage bill. It concludes that despite the increase in resources for municipal public education by Fundeb, there was a decrease in the percentage applied to the remuneration of teachers and the consequent devaluation of the professional Public Magisterium.
\end{abstract}

Keywords: Basic Education, Financing of Education, Educational Funds.

\section{INTRODUÇÃO}

O financiamento da educação e sua consequente proposição de política de fundos precisam ser compreendidos como uma política educacional pública; e como política pública, no embate entre as forças de trabalhadores, movimentos sociais e Estado, vêm ganhando ou não legitimidade na história da educação brasileira.A política de fundos na educação brasileira não é recente, estando na base da ideia de vinculação constitucional de recursos para a educação. 
A compreensão do financiamento da educação pública implica perceber este aspecto como totalidade de uma política de Estado e nas suas determinações com o mundo do trabalho e do capital.

As políticas educacionais concebidas nas últimas décadas do Século XX - e em desenvolvimento nesse início do Século XXI - devem ser compreendidas no âmbito das transformações econômicas, geopolíticas e culturais em curso no mundo capitalista contemporâneo. As reformas educativas implementadas atualmente, na maioria dos países da América Latina, são decorrentes, portanto, do processo de reestruturação pelo qual passa o capitalismo mundial sob a égide dos princípios do neoliberalismo (CABRAL NETO e RODRIGUEZ, 2007, p. 13).

Os determinantes sociais e históricos do capitalismo colocam a educação em submissão aos aspectos econômicos de uma sociedade. Implica perceber este problema numa historiografia marxista, numa visão materialista-dialética em que a política de fundos se coloca como um aspecto de uma totalidade muito mais complexa do processo histórico, para além da política educacional. A totalidade das estratégias de uma política educacional, expressa no financiamento da educação, se consolida em elementos de descontinuidade, localizadas e dependendo da conjuntura política de cada momento histórico, sendo que no aspecto legal, só ganharam legitimidade após a Constituição Federal de 1988.

Neste sentido, este artigo visa analisar as principais características da política de fundos, buscando desvelar os princípios da lógica de financiamento da educação básica pública implantada a partir da década de 1990, no contexto da reforma do Estado Capitalista. Partindo desta análise, poderá se compreender as dificuldades históricas para a ampliação dos gastos públicos em educação, principalmente a partir da aplicação do Produto Interno Bruto (PIB) na educação. Neste contexto de Reforma, busca-se também analisar a política de fundos no financiamento da educação pública brasileira na atualidade com a criação, a partir da década de 90, de dois fundos, Fundo de Manutenção e Desenvolvimento do Ensino Fundamental e de Valorização do Magistério (Fundef) e Fundo de Manutenção e Desenvolvimento da Educação Básica e de Valorização dos Profissionais da Educação (Fundeb), analisando seus limites na concretização de uma educação pública de qualidade, implicando muitas das vezes na valorização contábil da educação, em detrimento da qualidade do serviço ofertado como política pública.

A partir desta análise dos limites das políticas de fundos, busca-se demonstrar a aplicação dos ínfimos recursos destinados à educação pública pelo Fundeb, na valorização do Magistério Público de São Luís/MA, notando-se que desde o ano de implantação, em 2007, o poder público municipal, a cada ano, vem diminuindo o percentual de aplicação na remuneração do Magistério ${ }^{2}$.

\section{A POLÍTICA DE FUNDOS EDUCACIONAL RECENTE: A Perspectiva Contábil na Educação Versus a Qualidade do Ensino Público}

A educação situa-se no âmbito das transformações sociais, políticas, econômicas e culturais em curso no mundo capitalista no final do século XX e início do século XXI, sendo decorrentes das exigências da acumulação e da recomposição do capitalismo mundial, materializado nos princípios do neoliberalismo. As reformas propostas, a partir da década de 90, pelos organismos multilaterais e internacionais, bem representado pelo Banco Mundial (BM), são uma imposição em decorrência de acordos no financiamento e assessoria às políticas educacionais para os países da América Latina e Caribe. Nesse 
contexto, o Estado se coloca como Estado Mínimo e o centro da reforma estatal é o ajuste fiscal, com redução de gastos e o atendimento mínimo às políticas sociais, recorrendo à privatização ou à regulamentação do Terceiro Setor.

Essas reformas estão formuladas em vários documentos construídos internacionalmente por organismos multilaterais internacionais em parceria com os governos dos países da América Latina, destacando a importância do Projeto Principal da Educação (PPE), consolidado na Recomendação de Quito, em 1981 e que influenciou as formulações do Programa Educação Para Todos, 1990, na Conferência de Jomtien, tendo como objetivos principais: universalizar a educação básica, priorizando o ensino fundamental; erradicar o analfabetismo; e melhorar a qualidade e a eficácia dos sistemas educativos, principalmente os resultados de aprendizagem (CABRAL NETO, 2007).

Vale ressaltar que neste contexto das crises política e econômica do capitalismo, como elemento essencial de sua ideologia, faz-se necessário a recomposição do capital, impondo à política educacional o compromisso de melhorar a atenção educativa aos setores mais vulneráveis, aos grupos menos favorecidos (inicialmente considerava-se apenas o foco da pobreza, atualmente o foco são as chamadas minorias: etnias indígenas, jovens e adultos não alfabetizados, educação do campo, educação especial, gênero e etnico-raciais).

A oferta educativa, priorizando o atendimento aos grupos menos favorecidos, observa os princípios estabelecidos pelo neoliberalismo para as políticas sociais que pressupõem políticas focalizadas nos setores mais pobres e minorias da sociedade, afastando-se, portanto, de políticas de caráter universalista conforme defendem os setores progressistas.

As políticas implementadas na década de 80 estavam voltadas apenas para a dimensão quantitativa da educação, à superação da pobreza e da desigualdade educativa, sendo que a dimensão da qualidade da educação precisava avançar a partir da década de 90, pontuando elementos novos como a articulação do Estado com as organizações sociais com responsabilidade compartilhada pela educação pública, via privatização, voluntariado ou filantropização dos serviços educacionais. A proposta tem a intenção clara de valorizar a educação como investimento social e desenvolvimento econômico, considerando os dois aspectos principais da qualidade do ensino: a eficiência e a eficácia nos resultados da aprendizagem.

Os elementos centrais das reformas educacionais propostas nas políticas governamentais são: a descentralização, principalmente nos aspectos financeiro e administrativo; a avaliação de desempenho; a valorização docente; as reformas curriculares; e a gestão democrática. Impõem-se aos sistemas educacionais um novo modelo de gestão do Estado, considerando os processos de Centralização $\mathrm{x}$ Descentralização. A centralização das decisões de caráter estratégico-político da orientação educacional relativas à avaliação, às normas, ao currículo e ao financiamento são formuladas no âmbito central articulada politicamente pelas agências internacionais, sendo operacionalizadas tecnicamente no processo pedagógico do espaço escolar, descentralização administrativa e financeiro, apenas do fazer pedagógico, buscando-se as parcerias com as Organizações Não Governamentais (ONGS), famílias e comunidade (CABRAL NETO, 2007).

No início do século XXI, as políticas educacionais continuam sendo influenciadas, no contexto das reformas impostas pelos organismos internacionais aos governos latinoamericanos, inclusive o brasileiro, propostas considerando que a educação deveria 
fortalecer a escola pública, com foco na igualdade e na construção de sociedades mais inclusivas e equitativas, novamente como diretriz neoliberal da política social focalizada.

As políticas educacionais do novo século retomam as iniciadas nas décadas de $80 \mathrm{e}$ 90, redirecionadas pelo neoliberalismo, a partir do trinômio: Privatização, Focalização/Seletividade e Descentralização, mas traz novos elementos, que direcionam todos os aspectos do processo educacional (gestão, ensino, avaliação, financiamento) com foco em resultados, na aprendizagem, fortalecendo principalmente os protagonismo dos docentes e a participação das famílias e comunidades na qualidade da educação. Não é mais o estado, e sua política educacional, culpada pelos resultados da qualidade da educação, mas o olhar volta-se para dentro da escola, a gestão do processo de ensinar e de articular a comunidade.

O Estado Capitalista brasileiro historicamente não tem demonstrado compromisso com os interesses sociais educacionais da classe trabalhadora e o contexto da Reforma do Estado, a partir da década de 1990, só reforçou este descompromisso. Sendo assim, o Estado brasileiro vem apresentando particularidades fundadas numa lógica neoliberal que reforçam valores do patrimonialismo, no autoritarismo, na impermeabilidade às demandas sociais e na subordinação aos centros hegemônicos do capitalismo (DAVIES, 2008).

A reforma do Estado Capitalista, iniciada em 1995, com o Governo Fernando Henrique Cardoso (FHC), estabelece mudanças na ordem econômica, social e política, produzindo efeitos imediatos sobre a vida dos cidadãos. Esta reforma, baseada no Plano Diretor da Reforma do Aparelho do Estado (PDRAE)apresentado pelo Ministério da Administração e Reforma do Estado(MARE), aprovado em novembro de 1995 pela Câmara e pelo Conselho da Reforma do Estado, apresentou um diagnóstico da "crise" do Estado; definiu os objetivos, estabeleceu diretrizes para a reforma da administração pública e criou condições para uma reconstrução da administração vigente em "bases modernas e racionais, visando prepará-lo para o cenário globalizado e seus desafios" (BRASIL, 1995, p. 9-10).

O processo de reforma deve atingir os objetivos do neoliberalismo, estabelecendo um modelo de Estado Gerencial em oposição ao Estado patrimonialista que dominou a Administração Pública do Brasil no último século, caracterizado pela presença de poder muito concentrado, exagerada burocratização, nepotismo, empreguismo, excesso de cargos de confiança e desmedido controle político. A estratégia apontada pelo projeto de reforma é a de redefinir seu modo de intervenção na economia, "resgatar sua autonomia financeira e sua capacidade de implementar políticas públicas" (BRASIL, 1995, p. 16).

De acordo com este documento, a reforma do Estado deve redefinir o papel do Estado, que deixa de ser o responsável direto pelo desenvolvimento econômico e social, para apenas regular esse desenvolvimento. Reformar o Estado significa transferir para o setor privado as atividades que podem ser controladas pelo mercado. Através destas medidas o Estado reduz seu papel como responsável direto pelas políticas sociais, mas garante sua atuação como "gerenciador" ou regulador destes, dos quais destacamos os serviços voltados para a área social, educação e saúde (BRASIL, 1995, p. 17-18).

Conforme o documento, o Estado deixa de ser o responsável direto pelo desenvolvimento econômico e social, para fortalecer-se na função de regulação desse desenvolvimento, pois, o fato de ter no passado assumido funções diretas de execução a fim de atingir aos objetivos sociais e econômicos, engendraram distorções e ineficiências que justificaram a reforma em andamento que visa precipuamente privatizar e terceirizar os serviços educacionais (BRASIL, 1995, p. 17-18). 
Além da privatização o documento faz referência a terceirização, como estratégia de reforma do Estado, na implementação da política neoliberal de "desoneração do Estado, que procura transferir determinadas funções para o nível local como passo para a privatização, num processo perverso de descentralização e neolocalismo" (TEIXEIRA, 2002,p. 50). Assim longe de significar mais recursos para a educação, este projeto de reforma busca racionalizar recursos diminuindo o papel do Estado no que se refere às políticas sociais e consequentemente tornando-o máximo para o capital. A racionalidade financeira com os gastos públicos na implementação das políticas públicas educacionais, estará fundamentando a política educacional do pensamento neoliberal, consubstanciada na base legal da Lei de Diretrizes e Bases (LDB), lei $\mathrm{n}^{\circ}$ 9.424/1996, e nas leis que regulamentam a política de fundos, o Fundef e Fundeb.

No contexto de descentralização dos mecanismos de financiamento e gestão do sistema, a política de fundos, como concepção de financiamento da educação pública, estrutura-se como reformas educacionais propostas para a América Latina, a partir da década de 90, consolidada na elaboração do Plano Decenal de Educação para Todos, acordos na Conferência de Educação de Jomtien, colocando como desafio a ênfase ao trabalho docente, e, consequentemente a melhoria da qualidade da educação pública. A presença de órgãos multilaterais foi decisiva para definir as políticas educacionais na América Latina e vincula diretamente a melhoria dos índices sociais à qualidade da educação, indicando a política de fundos como resolução dos problemas de financiamento da educação pública.

No Brasil, a política de financiamento foi estruturada principalmente a partir do Fundef e Fundeb. Neste sentido, a política de financiamento da educação pública brasileira, organizada a partir da política de fundos faz todo o sentido no modelo neoliberal, no qual o Estado assume uma função de descentralização dos recursos, propondo apenas a redistribuição dos recursos constitucionalmente vinculados, sem uma proposição efetiva de aumento dos recursos públicos para a Educação Básica (DAVIES, 2004).

Os dois fundos formais que foram implantados, após a década de 90, têm característica de fundos de natureza contábil que redistribui $20 \%$ dos recursos já constitucionalmente vinculados à educação entre governos estaduais e municipais, com base no número de matrículas, tornando obrigatório pela primeira vez o gasto de $60 \% \mathrm{com}$ pagamento de professores. No ano de 1996 foi implantado o Fundef, regulamentado pela lei 9.424/96, destinado apenas ao Ensino Fundamental. Em substituição ao Fundef, foi criado o Fundeb, regulamentado pela lei 11.494/07, ampliando sua atuação para toda a Educação Básica. Esses dois fundos criados tiveram apenas o caráter redistributivo dos recursos já vinculados à manutenção do ensino e mantiveram o caráter supletivo da União na responsabilidade de ampliação dos recursos necessários na melhoria da oferta de ensino.

Pinto e Adrião (2007) apontam que o Fundef e o Fundeb não deram conta de elevar a melhoria da educação pública, mesmo que seja das condições da Educação Básica, ficando apenas na exigência legal, da aplicação dos recursos mínimos necessários na manutenção do ensino.

Ao optar por um determinado formato de financiamento, o poder público está, mesmo que não explicitamente, pressupondo e implementando as condições que permitam seja alcançado certo padrão de qualidade para educação ofertada. No Brasil, até o momento, o padrão de qualidade está 
diretamente relacionado aos recursos mínimos disponibilizados pela vinculação constitucional (PINTO e ADRIÃO, 2007, p. 42).

A análise da política de financiamento da educação proposta pelo Estado via política de fundos considera também que os diferentes instrumentos de regulamentação e operacionalização se sustentam numa política educacional proposta pelo governo LULA, com o lançamento do Plano de Desenvolvimento da Educação (PDE), em 2007, que define as diretrizes para a educação pública brasileira em quatro grandes áreas (educação básica, educação superior, educação profissional-tecnológica e alfabetização). Saviani (2009) aponta que na primeira área relacionada ao nível da educação básica, se desdobra em quatro aspectos: Formação de professores e piso salarial nacional; Financiamento (salárioeducação e Fundeb); Avaliação e responsabilização (o Índice de Desenvolvimento da Educação Básica - Ideb); e Plano de Metas (planejamento e gestão educacional).

O PDE se sustenta em dois pilares, o técnico e o financeiro. Do ponto de vista técnico, apóia-se em dados estatísticos referentes ao funcionamento das redes escolares de educação básica e em instrumentos de avaliação construídos a partir de indicadores do aproveitamento dos alunos e expressos nas provas aplicadas regularmente sob coordenação do Inep, a partir dos quais foi elaborado o Ideb. Do ponto de vista financeiro, os recursos básicos com que conta o PDE são aqueles constitutivos do Fundeb.

Vale reconhecer que o Fundeb representa considerável avanço em relação ao fundo anterior, o Fundef, ao promover a ampliação em toda a Educação Básica. Mas é preciso reconhecer também que o Fundeb não representou aumento dos recursos financeiros. Ao contrário, o número de estudantes atendidos pelo Fundo aumentou de 56,6\% e o montante do Fundo passou de 35,2\% bilhões para 48 bilhões, o que significa um acréscimo de apenas 36,3\%. Também a complementação da União não implicou acréscimo, pois deveria entrar com 30\% de seu orçamento. Ora, o orçamento do MEC para 2007, após o corte de 610 milhões imposto pela Fazenda, foi de 9 bilhões e 130 milhões. Logo, 30\% corresponderiam a 2 bilhões e 739 milhões. No entanto, a importância prevista como complementação da União para 2007 limitou-se a 2 bilhões (SAVIANI, 2009).

Em suma, o Fundeb é um fundo de natureza contábil que não chega a resolver o problema do financiamento da educação. Representa um ganho de gestão; porém, não um ganho financeiro. Na verdade, os recursos nele alocados, se efetivamente aplicados e corretamente geridos, podem melhorar o financiamento da educação comparativamente à situação anterior, mas não terão força para alterar o status quo vigente. Ou seja: uma boa gestão do fundo permitirá atender a um número maior de alunos, porém em condições não muito menos precárias do que as atuais, isto é, com professores em regime de hora-aula; com classes numerosas; e sendo obrigados a ministrar grande número de aulas semanais para compensar os baixos salários que ainda vigoram nos estados e municípios (SAVIANI, 2009, p.35).

A defesa do Fundeb como política educacional para o financiamento da educação pública vem trazer aspectos provincianos da origem dos fundos, apenas vinculando os recursos mínimos para a educação, sem ampliar o investimento numa qualidade da oferta em todos os níveis da educação.

Para demarcar os limites da política de fundos, duas posições são apontadas. Juca Gil se posiciona a favor da permanência de um fundo voltado ao financiamento da 
educação, pois o Fundef e Fundeb forçam a colaboração conjunta entre os entes federativos e os percentuais considerados suficientes a serem investidos em educação, mas ressalva que mesmo criando mecanismos de redistribuição de recursos e novos modelos de gestão, não representam maior aporte de recursos (ARELARO e GIL, 2006).

Contrapondo-se à política de fundos Lisete Arelaro (2006) ressalta que a política de fundos acaba se constituindo num mecanismo de transferência de responsabilidade da esfera federal para as esferas menores e avalia que o Fundef,

não passou de competente estratégia para transferir aos Municípios responsabilidades até então da União e dos Estados e manter, ao custo mais baixo que for tolerável para as crianças pobres - e só para elas uma escola pobre (...) nunca o Governo Federal gastou, de forma tão competente, tão pouco no ensino fundamental (ARELARO e GIL, 2006, p. 83).

Como avalia Cury (2007), ao longo da história da educação brasileira, resultando na atual forma de vinculação de recursos do financiamento da educação, mantiveram-se três vertentes na concepção social de Estado, tensionado num modelo liberal: no âmbito legal, no elo entre Constituição, impostos e recursos vinculados; no âmbito técnico, na presença de uma burocracia estatal que estabelece parâmetros estatísticos e contábeis para tomada de decisões em relação às políticas educacionais; e no âmbito empresarial, nas relações que se estabelece entre Estado e Capital, principalmente considerando a apropriação particular dos recursos da educação pública.

Sendo assim para a real melhoria da educação pública se faz urgente a ampliação dos recursos alocados aos fundos contábeis, já que não significam a totalidade dos recursos destinados à educação, bem como, a busca de novas fontes de receitas constituindo-se em estratégias para que valores baixos não sejam praticados, acentuando ainda mais as desigualdades sócio-educacionais em todo o país.

Como avalia Saviani (2008), a ideia motriz para a melhoria da educação pública está na defesa de um Sistema Nacional de Educação, consolidado em outro Plano Nacional de Educação que considere as bandeiras históricas da luta por uma política social séria e decente, sendo que a defesa de $10 \%$ do PIB se torna a única saída.

Em suma, para enfrentar os problemas que foram acumulando-se, os recursos orçamentários regulares não são suficientes. Impõe-se um plano de emergência que permita investir maciçamente, elevando-se substancialmente e em termos imediatos o percentual do PIB destinado à educação. Esta há de ser a ideia-força, o eixo central do PNE que devemos propor (SAVIANI, 2008, p. 232).

Essa ideia motriz vem sempre impulsionando as lutas em defesa da educação pública como aconteceu na "Campanha Nacional dos 10\% do PIB para a Educação Pública já!"3, realizada em 2011 pelos diferentes movimentos, sindicatos e coletivos de defesa da qualidade na educação pública. Atualmente, a proposta de ampliação dos investimentos em educação se coloca como prerrogativa no novo Plano Nacional de Educação - PNE, aprovado em 2014, mas que ainda coloca a meta de aplicação dos 10\% do PIB na educação apenas ao final do plano; vale ressaltar que foi retirada a palavra pública de educação, o que sinaliza a aplicação de recursos na parceria público e privado. 


\section{FUNDEB E OS INVESTIMENTOS NA EDUCAÇÃO PÚBLICA MUNICIPAL: A Remuneração do Magistério de São Luís/Ma no Centro do Debate}

Ao longo das análises já desenvolvidas destaca-se que, sejam em nível regulamentar ou em nível da correlação de forças políticas existentes,uma política de financiamento da educação pública deve englobar a defesa de uma política de valorização do professor, sendo que alguns aspectos devem ser considerados importantes nesta valorização, e encontram resistência para sua concretização diante dos limites da política educacional imposta.

Para efeito de recorte de análise da política de financiamento da educação e da valorização profissional do Magistério Público, considerar-se-á o Fundeb, em nível municipal,em São Luís/MA, e as aplicações do mesmo com os investimentos na remuneração do profissional do Magistério ${ }^{4}$, no período de 2007-2013, a partir da base de dados do Siope ${ }^{5}$.

De início vale ressaltar que a base de dados do Siope, informa apenas a aplicação dos recursos destinados ao Fundeb para a Rede Pública Municipal de São Luís- MA, deixando limites na compreensão da política de financiamento, já que não engloba os outros recursos destinados a Manutenção e Desenvolvimento do Ensino (MDE), tornando mais difícil o acesso detalhado a todas as despesas realizadas pela Prefeitura com a educação pública, desde os recursos do Fundeb, como os do salário educação e os outros recursos para a $\mathrm{MDE}^{6}$.

No âmbito legal, os governos municipais devem aplicar no mínimo $25 \%$ dos impostos e transferências vinculados constitucionalmente. A Tabela 1 apresenta os dados dessa aplicação em nível municipal, no período de 2008-2013:

Tabela1: Aplicação de 25\% dos impostos vinculados a MDE no âmbito municipal, 2008-2013

\begin{tabular}{c|c|c|c|c|c}
\hline $\mathbf{2 0 0 8}$ & $\mathbf{2 0 0 9}$ & $\mathbf{2 0 1 0}$ & $\mathbf{2 0 1 1}$ & $\mathbf{2 0 1 2}$ & $\mathbf{2 0 1 3}$ \\
\hline $25,12 \%$ & $27,43 \%$ & $30,36 \%$ & $30,28 \%$ & $22,06 \%$ & $26,04 \%$ \\
\hline
\end{tabular}

Fonte: Elaboração da autora com base dos dados do Siope, 2008-2013

Nos anos de 2010 e 2011, o município de São Luís, alcançou os patamares mais elevados de aplicação dos recursos vinculados constitucionalmente, passando de $30 \%$. No entanto, no ano de 2012, a aplicação dos recursos pelo governo municipal foi inconstitucional, abaixo dos $25 \%$ regulamentados na Constituição Federal de 1988, alcançando os irrisórios 22,06\%.

Não existe nenhum mecanismo de cobrança dessa aplicação ou punição do governo, apesar da criação de muitos mecanismos de transparência e controle criados no século $\mathrm{XXI}^{7}$, mas ainda não se tem um detalhamento das contas públicas gastas para a educação brasileira, fato observado em toda greve, quando os representantes da categoria do Magistério debatem as condições docentes em mesas de negociação e os representantes do governo apresentam apenas números amplos, já divulgados no Siope e não detalham os gastos com folha de pagamento e/ou outras despesas com educação.

Estudos sobre o papel dos Tribunais de Contas na fiscalização da aplicação dos recursos destinados a MDE lembram da importância e necessária cobrança e fiscalização sobre o cumprimento do que determinava a legislação, não esquecendo de estabelecer o mínimo a ser cumprido. Para se ter uma melhoria na educação escolar é necessário que os 
governantes invistam além do mínimo estabelecido, embora nem isso façam (DAVIES, 2008).

No caso de São Luís, o que se observa é a inconstitucionalidade na aplicação do mínimo exigido de $25 \%$ na educação. Ao observar a previsão de aplicação dos recursos destinados a toda MDE para o ano de 2014, definidos na Lei de Orçamento Anual (LOA), o percentual destinado à educação pública municipal é de apenas 19,65\%, não atingindo os 25\% previstos na Constituição Federal de 1988 e na LDB de 1996.

Para compreender melhor a parte do orçamento público que cabe à educação a Tabela 2 discrimina os valores de cada área em ordem de prioridades, valores definidos pela LOAdo município de São Luís (MARANHÃO, 2014).

Tabela 2: Orçamento da Prefeitura de São Luís, 2014

\begin{tabular}{c|l|c|c}
\hline ORDEM & \multicolumn{1}{|c|}{ ÁREA/ÓRGÃO } & VALOR (R\$) & $\%$ \\
\hline 01 & SAÚDE & $638.398 .088,00$ & 23,61 \\
\hline 02 & EDUCAÇÃO & $531.484 .979,00$ & 19,65 \\
\hline 03 & OBRAS E SERVIÇOS & $424.561 .838,00$ & 15,70 \\
\hline 04 & RECURSOS PARA SEMFAZ E SEMAD & $312.222 .854,00$ & 11,55 \\
\hline 05 & SEMAD E IPAM & $257.382 .470,00$ & 9,52 \\
\hline 06 & TRÂNSITO E TRANSPORTES & $101.077 .869,00$ & 3,74 \\
\hline 07 & PREFEITURA & $93.620 .848,00$ & 3,45 \\
\hline 08 & SEC. PROJETOS ESPECIAIS & $77.865 .494,00$ & 2,88 \\
\hline 09 & CÂMARA MUNICIPAL & $75.383 .933,00$ & 2,79 \\
\hline 10 & ASSISTÊNCIA SOCIAL & $39.310 .939,00$ & 1,46 \\
\hline 11 & URBANISMO E HABITAÇÃO & $37.192 .973,00$ & 1,38 \\
\hline 12 & SEMFAZ & $28.476 .172,00$ & 1,05 \\
\hline 13 & SEPLAN & $23.775 .197,00$ & 0,89 \\
\hline 14 & AGRICULTURA, PESCA E ABASTECIMENTO & $11.804 .877,00$ & 0,44 \\
\hline 15 & RESERVA DE CONTIGÊNCIA & $11.483 .788,00$ & 0,42 \\
\hline 16 & TURISMO & $10.547 .151,00$ & 0,40 \\
\hline 17 & SEGURANÇA ALIMENTAR & $10.430 .418,00$ & 0,39 \\
\hline 18 & INFORMAÇÕES E TECNOLOGIA & $9.671 .923,00$ & 0,36 \\
\hline 19 & DESPORTO E LAZER & $5.103 .649,00$ & 0,20 \\
\hline 20 & MEIO AMBIENTE & $3.747 .881,00$ & 0,11 \\
\hline 21 & ORÇAMENTO PARTICIPATIVO & $405.550,00$ & 0,01 \\
\hline
\end{tabular}

Fonte: Prefeitura de São Luís, LOA, 2014

Ao analisar os dados do Orçamento na Tabela 2, nota-se que os cinco maiores orçamentos vão para as áreas de Saúde, Educação,Obras e Serviços, Recursos para Secretaria Municipal de Fazenda (Semfaz) e Secretaria Municipal de Administração (Semad), Semad/Instituto de Previdência e Assistência do Município (Ipam). A Educação é responsável pelo segundo maior orçamento, com um valor de $\mathrm{R} \$ 531.484 .974,00$, no entanto ainda comprometendo apenas $19,65 \%$ do mesmo.

Um aspecto interessante é que a Câmara Municipal está entre os 10 primeiros órgãos a ter prioridade no orçamento, levando um valor de $\mathrm{R} \$ 75.383 .933,00$, o que corresponde em relação ao orçamento da educação a $7^{a}$ parte deste valor (MARANHÃO, 2014).

Para melhor compreensão dos gastos públicos seria interessante verificar as despesas de cada rubrica para observar o investimento que a Prefeitura realiza em cada área de atendimento. No entanto, somente com os valores reais já se tem uma dimensão do valor que tem a educação no Fundo público. 
Este detalhamento da divisão dos recursos destinados aos diferentes órgãos do poder público municipal é melhor informado no Gráfico 1 , indicando as prioridades da Prefeitura com os gastos públicos para o ano de 2014.

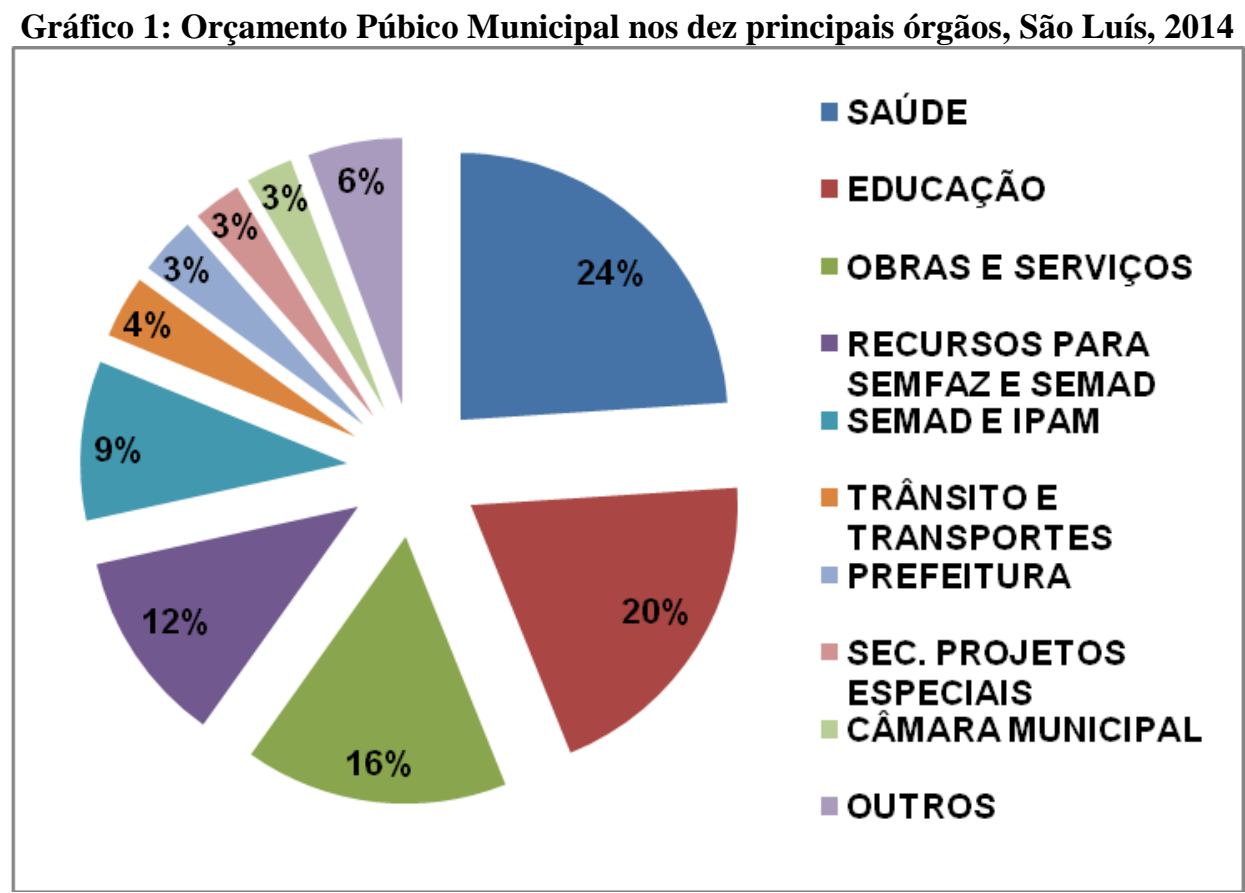

Fonte: Prefeitura de São Luís,LOA, 2014

Ao observar a distribuição dos recursos do Orçamento público municipal de São Luís, em percentuais exatosno Gráfico1, entre os órgãos que mais tem recursos nota-se uma distribuição desigual, já que os atendimentos mais prioritários, como educação e saúde, ficam apenas com $44 \%$, e detalhando melhor esse percentual verifica-se anteriormente na Tabela 2 que parte do recurso destinado à educação não pertence a esta rubrica.

O orçamento da educação compete com percentuais altos destinados aos órgãos de Obras e Serviços, com 16\%, recursos para a Semfaz e Semad, 12\% e para Semad/Ipam, $8 \%$. A análise das rubricas detalhadas de cada órgão demonstraria claramente a destinação desses recursos e os problemas injustos das prioridades que a Prefeitura de São Luís vem dando ao Orçamento público às políticas sociais.

O detalhamento do valor destinado à Educação Municipal de São Luís, em 2014, foi discriminado no Plano Prurianual (PPA), prevendo os gastos do Orçamento Público conforme Tabela 3 é distribuído da seguinte forma:

Tabela 3: Orçamento da Educação na Prefeitura de São Luís, 2014

\begin{tabular}{|c|c|c|}
\hline UNIDADE & VALOR (R\$) & $\%$ \\
\hline MDE & $223.865 .529,00$ & 42 \\
\hline FUNDEB & $295.049 .776,00$ & 56 \\
\hline FUNDAÇÃO MUNICIPAL DE CULTURA & $10.869 .674,00$ & 1,76 \\
\hline FUNDO MUNICIPAL DE CULTURA & $1.700 .000,00$ & 0.24 \\
\hline VALOR TOTAL & \multicolumn{2}{|c|}{$531.484 .979,00$} \\
\hline
\end{tabular}

\section{Fonte: Prefeitura de São Luís/PPA 2014}

Um dado é interessante notar que os recursos do Fundeb representam $56 \%$ do valor total destinado à educação pública municipal. Evidencia-se que os outros recursos 
destinados a MDE precisam ser mais bem investigados, pois como já foi apontado anteriormente, os governantes apenas anunciam que o Fundeb é o recurso principal para se aplicar na valorização do Magistério; e os outros 44\% dos recursos? O Gráfico 2 demonstra essa divisão dos recursos destinados a MDE em São Luís, prevista para 2014.

Gráfico 2: Orçamento Púbico Municipal na Educação, São Luís, 2014

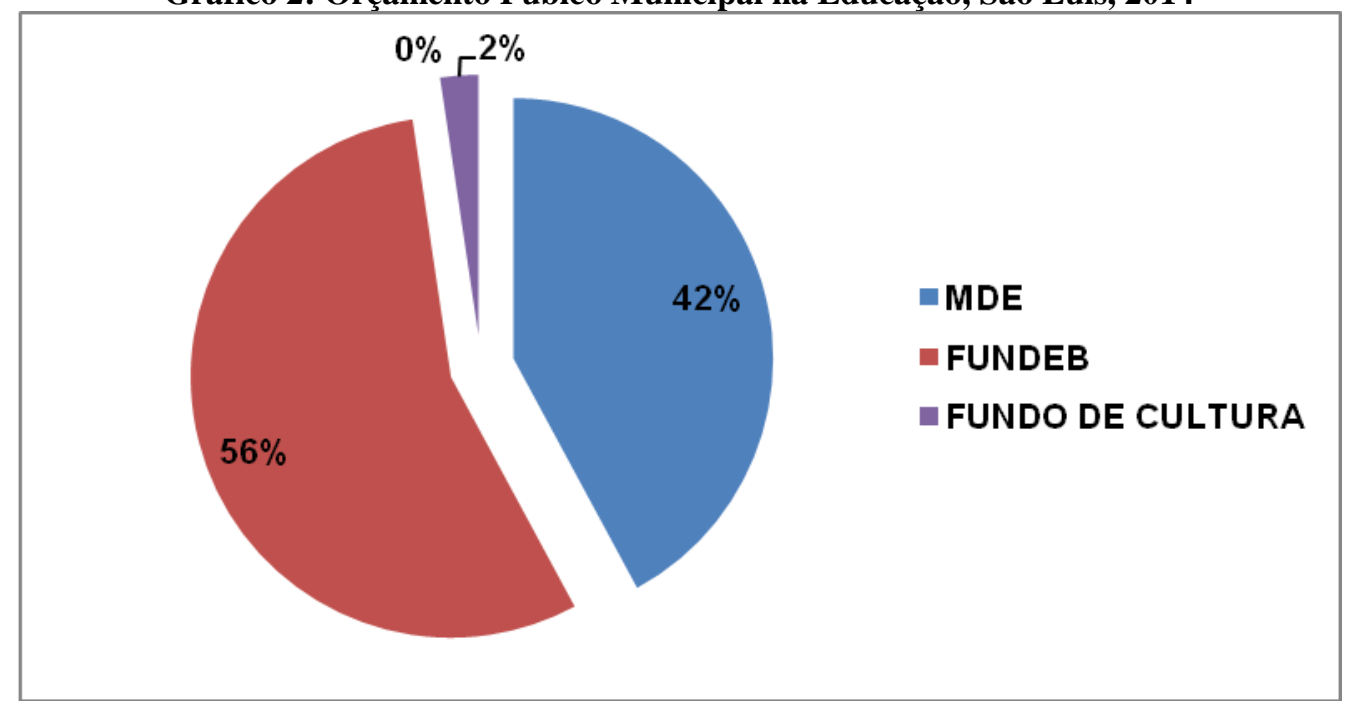

Fonte: Prefeitura de São Luís, LOA, 2014

Outro aspecto interessante mostrado no Gráfico 2é que parte do recurso da educação vai para a Cultura, cerca de $2 \%$, o que não configura despesas com educação. Faz-se necessário detalhar melhor o Orçamento Público e definir as rubricas para verificar se é constitucional essa aplicação do recurso da educação na Cultura. Neste sentido, serão detalhados melhor os recursos destinados ao Fundeb para a educação pública municipal em São Luís-MA, no período de 2007 a 2013.

O Fundeb foi implantado em 2007, no município de São Luís, para atender às despesas públicas com a Educação Básica, incluindo pagamento dos profissionais do Magistério, conforme determina a lei. A Rede Pública Municipal atende à Educação Básica, da Educação Infantil ao Ensino Fundamental, nas modalidades da Educação Especial e Educação de Jovens e Adultos. Desde a implantação do Fundeb até o ano de 2013, a Tabela 4 apresenta a receita total aplicada:

Tabela 4: Receita do Fundeb em São Luís/MA, 2007-2013

\begin{tabular}{c|c|c}
\hline ANO & RECEITA TOTAL $(\mathbf{R} \mathbf{)}$ & $\begin{array}{c}\text { AUMENTO DE UM ANO } \\
\text { A OUTRO (\%) }\end{array}$ \\
\hline 2007 & $78.531 .297,50$ & - \\
\hline 2008 & $108.928 .423,49$ & 38,56 \\
\hline 2009 & $138.544 .797,81$ & 27,04 \\
\hline 2010 & $144.848 .251,77$ & 4,54 \\
\hline 2011 & $215.421 .031,64$ & 42,53 \\
\hline 2012 & $241.003 .242,26$ & 12,75 \\
\hline 2013 & $243.544 .070,25$ & $3,45 \%$ \\
\hline
\end{tabular}

Fonte: Elaboração da autora com base nos dados do Siope, 2007-2013

Os dados mostram que os valores destinados à Rede Municipal sofrem variações durante os anos, mas que definem um valor anual contínuo e crescente, em milhões. Apenas nos anos de 2010, 2012 e 2013 houve um percentual baixo de acréscimo em 
relaçãoao valordo ano anterior. Parao ano de 2013, foi feito um repasse de R\$ 243.544.070,25. Esse foi o valor mais recente informado na base de dados do Siope.

O Gráfico 3 confirma essa evolução crescente dos recursos do Fundeb destinados à Prefeitura de São Luís e indicam que a cada ano, desde a implantação do referido fundo, em 2007, os recursos só aumentam, evoluindo em 2007 de $\mathrm{R} \$ 78$ milhões e meio ao valor de mais de $\mathrm{R} \$ 243$ milhões e meio, mais que o triplo do valor no início de implantação do Fundeb.

Gráfico 3: Evolução do Fundeb na rede pública municipal, São Luís/MA, 2007-2013

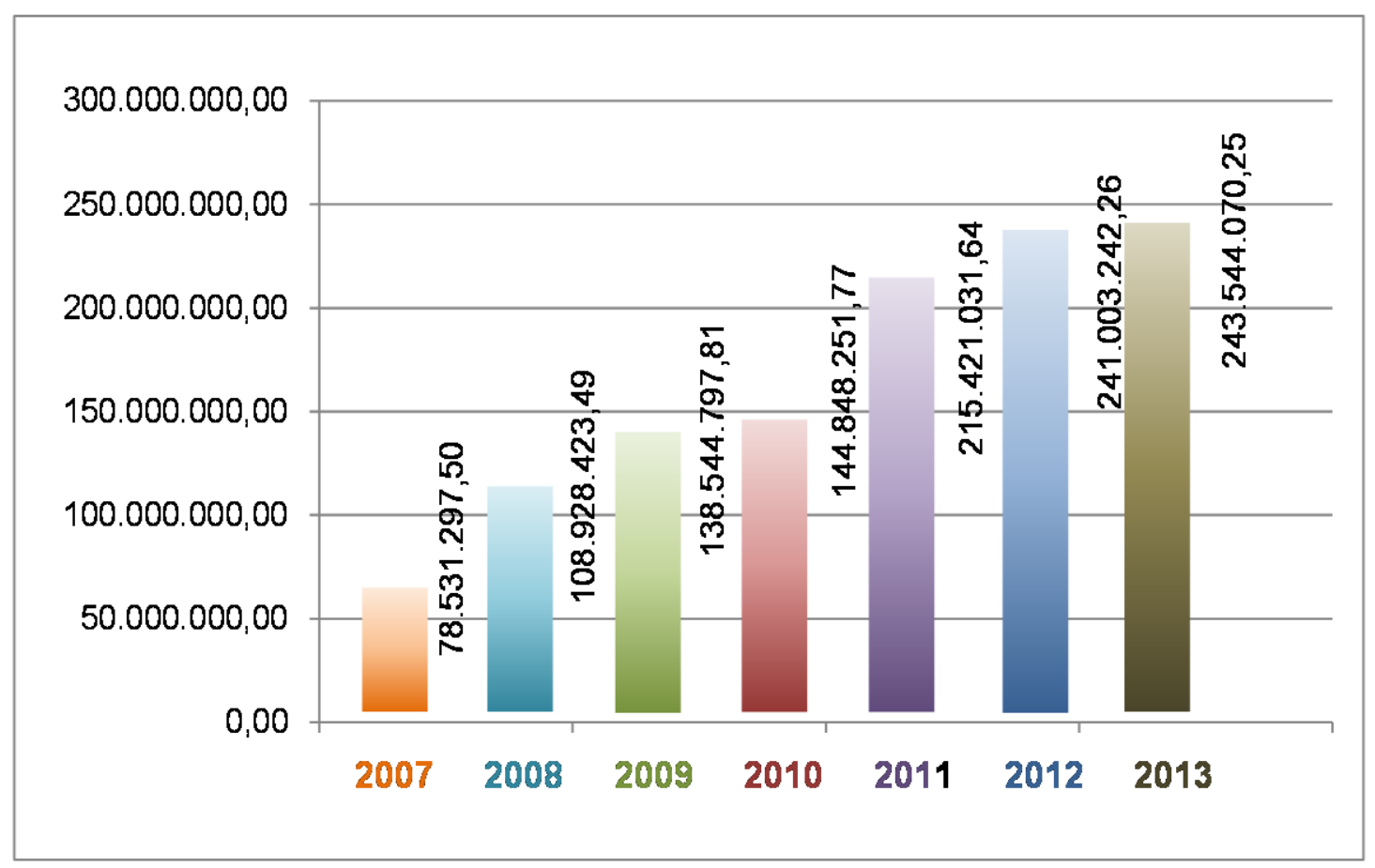

Fonte: Elaboração da autora com base nos dados do Siope, 2007-2013

Em relação ao cumprimento do art. 22 da Lei do Fundeb, que estabelece a aplicação dos recursos do fundo na remuneração dos professores de no mínimo $60 \%$, os dados da Tabela 5 evidenciam o cumprimento deste dispositivo, variando ano a ano.

Tabela 5: Aplicação do Fundeb nas despesas com educação públicamunicipal, São Luís/MA, 2007-2013

\begin{tabular}{c|c|c|c|c|c}
\hline ANO & $\begin{array}{c}\text { RECEITA } \\
\text { TOTAL (R\$) }\end{array}$ & $\begin{array}{c}\text { REMUNERAÇÃO } \\
\text { DO MAGISTÉRIO } \\
(\mathbf{R} \$)\end{array}$ & $\begin{array}{c}\text { APLICAÇÃO } \\
\text { DE 60\% }\end{array}$ & $\begin{array}{c}\text { OUTRAS } \\
\text { DESPESAS } \\
\text { (R\$) }\end{array}$ & $\begin{array}{c}\text { APLICAÇÃO } \\
\text { DE 40\% }\end{array}$ \\
\hline 2007 & $78.531 .297,50$ & $70.722 .805,82$ & 90,05 & $5.772 .836,08$ & 7,35 \\
\hline 2008 & $108.928 .423,49$ & $93.853 .797,03$ & 86,16 & $15.074 .626,46$ & 13,83 \\
\hline 2009 & $138.544 .797,81$ & $124.643 .149,90$ & 89,96 & $13.853 .254,52$ & 9,99 \\
\hline 2010 & $144.848 .251,77$ & $127.111 .106,75$ & 87,75 & $17.737 .145,02$ & 11,34 \\
\hline 2011 & $215.421 .031,64$ & $175.600 .823,62$ & 81,51 & $33.721 .986,83$ & 15,08 \\
\hline 2012 & $241.003 .242,26$ & $205.219 .775,53$ & 82,65 & $46.603 .568,01$ & 16,83 \\
\hline
\end{tabular}

Fonte: Elaboração da autora com base nos dados do Siope, 2007-2013

No primeiro ano de aplicação do Fundeb, em 2007, observa-se que foi aplicado o percentual maior com a remuneração do Magistério, chegando a 90,05\% e que o menor 
valor pago foi de 77,67\%, em 2013, de gastos com pagamento de profissionais do Magistério.

Esta característica de investimento com incidência decrescente na valorização do Magistério foi denunciado na greve de 2013, pela Setorial da Educação da CSPConlutas, em que reafirmava que a cada ano a Semed vinha gastando menos com o pagamento de professores, conforme visualizado no Gráfico 4 (MARANHÃO, 2013).

Gráfico 4: Aplicação do Fundeb com a remuneração do Magistério público municipal, São Luís/MA, 2007-2013

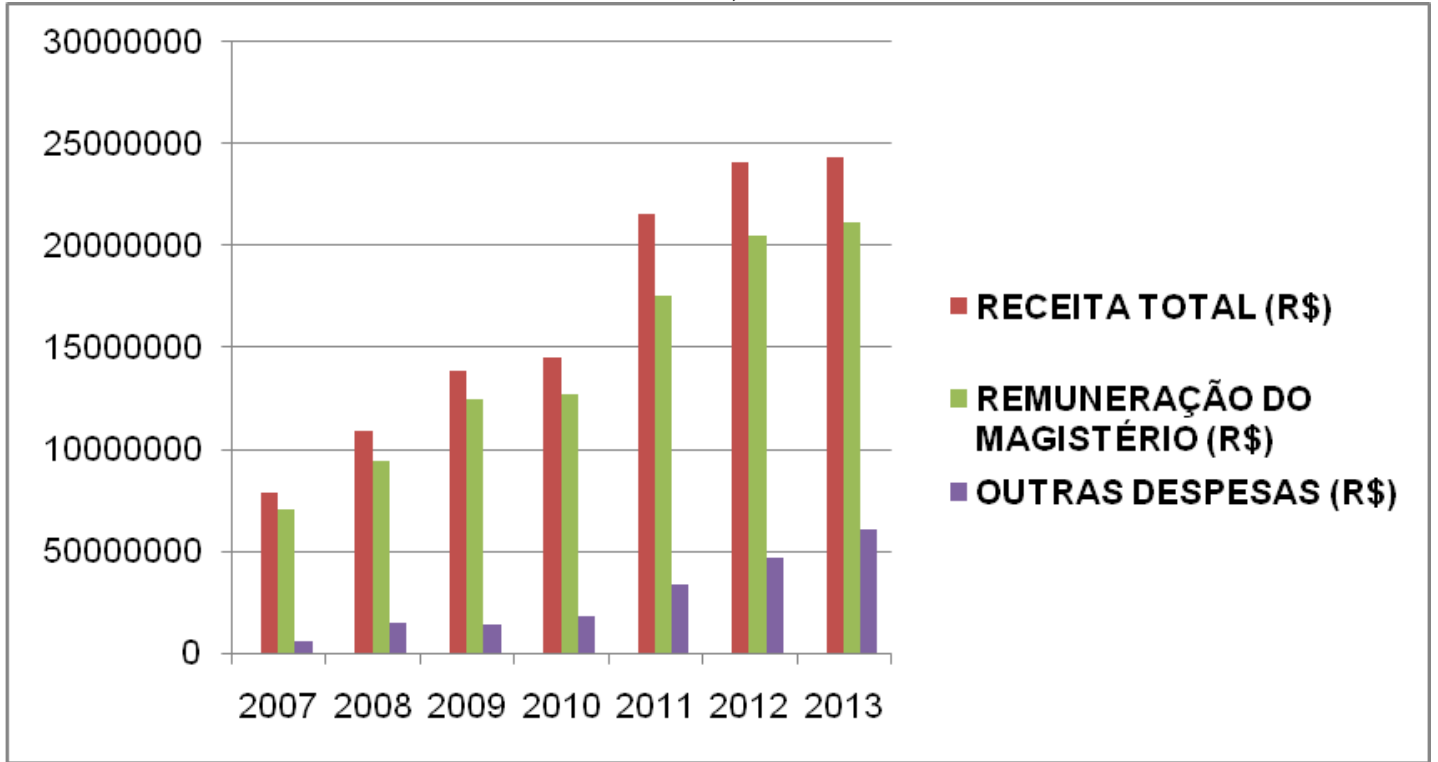

Fonte: Elaboração da autora com base nos dados do Siope, 2007-2013

Os dados demonstram um movimento de decréscimo dos percentuais com a remuneração a cada ano, o que leva a considerar que a meta da política municipal para o financiamento da educação é de alcançar os patamares mínimos propostos na lei, ou seja, $60 \%$. A cada ano são gastos valores cada vez menores com a valorização salarial do professor, pois o dado mais recente (ano de 2013) preocupa ainda mais, indicando o percentual mais baixo gasto com essa remuneração, com a aplicação de apenas $77,67 \%$ do valor total da receita do Fundeb.

O que se observa é que muitos governos, incluindo a Prefeitura de São Luís, vem tendo a mesma estratégia em relação aos recursos do Fundeb, como ressaltava Davies (2008), de que nas discussões e negociações sobre melhoria salarial ou valorização do Magistério, limitaram-se aos 60\%, não levando em conta os demais recursos vinculados a MDE. Os governos comodamente transformam o mínimo em máximo.

Sendo assim, a Prefeitura de São Luís já vem demonstrando uma característica da maioria dos governos municipais, de aplicar apenas o mínimo regulamentado: o mínimo de aplicação dos impostos constitucionalmente vinculados, no ano de 2014 previsto apenas 19,65\%, conforme o PPA; na remuneração dos professores, com apenas 77,67\% dos recursos do Fundeb.

Ora, a referência para uma educação de qualidade para todos não pode ser o percentual mínimo dos impostos, mas sim no mínimo este percentual. Não é por acaso que a imensa maioria dos governos alegam aplicar 
apenas o percentual mínimo, como se isso fosse suficiente para atender as necessidades educacionais da população (DAVIES, 2004, p.46).

A luta que a categoria do Magistério também empenha no financiamento da educação pública indica, neste item de aplicação dos recursos, que não se tem a certeza que são destinados ao pagamento dos profissionais em efetivo exercício do Magistério, e a não inclusão do pagamento de outros profissionais, inclusive os aposentados, item previsto na Lei do Fundeb. Para a análise deste aspecto se faz necessário o acesso à folha de pagamento detalhada, a ser fornecida pela Prefeitura de São Luís.

\title{
PARA ALÉM DA POLÍTICA DE FUNDOS: Na Defesa De Uma Política De Financiamento Decente Que Valorize A Educação Pública
}

Os diferentes instrumentos de regulamentação da política educacional vêm colocando a educação como elemento essencial para a melhoria dos índices sociais, desde a Constituição de 1988, passando pela LDB, reforçado no novo PNE. No aspecto legal são garantidos vinculação de recursos para suprir a manutenção das despesas com educação. A década de 90 se coloca como década de defesa da educação pública, diante das pressões e correlação de forças dos diferentes movimentos e organizações políticas e sociais. Foi consolidado o Fundef que representou a formalização da vinculação constitucional dos ínfimos recursos destinados à educação, consolidando como política educacional, no aspecto do financiamento, a política de fundos, que como já foi abordado apresenta-se apenas como natureza contábil de ação redistributiva e não garante a ampliação de recursos por parte da União.

Na continuidade de não abandonar os limites do Fundef e de uma política restrita de financiamento da educação pública, Jamil Cury (2007) aponta duas iniciativas: o primeiro é o Fundeb, que amplia a abrangência de atendimento para toda a Educação Básica, ampliando matrículas, sem ampliação substancial dos recursos; o segundo é o PDE, que tenta substituir o debate em torno do novo PNE e articula diferentes metas pactuadas por todos os entes federativos com foco voltado para resultados.

\begin{abstract}
O aumento do percentual investido em educação já era uma exigência dos movimentos de luta em defesa da escola pública, desde os CONEDs que avançaram no debate da construção de um Sistema Nacional de Educação e de um Plano Nacional de Educação que se envolve todos os níveis e modalidades de ensino. A sugestão ao MEC é que a linha mestra do PDE seja uma medida de impacto que permita imediatamente mudar a situação das escolas e levantar o ânimo dos professores, que passariam a desenvolver suas atividades com entusiasmo e dedicação. Para viabilizar essa mudança, propus, em 1997, para o PNE, que se dobrasse imediatamente o percentual do PIB investido em educação, passando dos atuais cerca de $4 \%$ para $8 \%$. Com esta proposta, teríamos para a educação básica uma possibilidade de investimento de 162 bilhões e 760 milhões de reais, portanto, mais do que o triplo (3,39 vezes) dos 48 bilhões previstos pelo FUNDEB para o ano de 2007 (SAVIANI, 2007, p. 43).
\end{abstract}

Atualmente o debate a ser colocado pela Campanha Nacional em defesa dos $10 \%$ do PIB para a educação pública avalia que os valores mencionados anteriormente indicam que só assim haveria recursos suficientes para tratar a educação com a devida seriedade e de acordo com a prioridade que é proclamada nos discursos, mas nunca efetivamente considerada. 
Outro debate a ser aprofundado e que reforça essa ideia motriz de que somente com a ampliação dos recursos para a educação é que de fato aconteceriam as mudanças no Sistema Nacional de Educação, envolvendo os três níveis de ensino, é a reforma tributária e fiscal.

O Instituto de Pesquisa Econômica Aplicada (Ipea), em documento recente faz uma análise do diagnóstico educacional, principalmente da atual expansão do ensino em todos os níveis e reforça que para alcançar as metas propostas pelo atual PNE somente com o aumento dos percentuais de fontes tributárias, bem como, aponta outras fontes possíveis de financiamento não tributárias, incluindo impostos que incidam sobre as Grandes Fortunas. Outra proposta seria o aumento da vinculação, de $18 \%$ para $20 \%$ da União e de $25 \%$ para $30 \%$ dos Estados e Municípios.

A atual capacidade de financiamento é insuficiente para viabilizar alternativas mais ousadas de ampliação da oferta e melhoria da qualidade da educação. Nesse sentido, apresentam-se a seguir algumas sugestões de possibilidades de financiamento para ampliação dos gastos em educação. Essas possibilidades podem ser de cinco tipos:tributários; rendas do présal; folga fiscal; outras fontes não tributárias; e de melhorias de gestão e controle social dos gastos públicos (IPEA, 2011, p.18).

A Tabela 6 organiza as propostas do Ipea para a ampliação dos recursos destinados à educação e que com apenas o aumento de alguns percentuais de alguns impostos se chegaria a aplicação de $10 \%$ do PIB na educação, incluindo diferentes tipos de tributação já existentes.

Tabela 6: Possibilidades de financiamento para os gastos do PIB em educação no Brasil propostas pelo Ipea para $2011^{8}$

\begin{tabular}{l|c}
\multicolumn{1}{c|}{ POSSIBILIDADES DE FINANCIAMENTO } & $\begin{array}{c}\text { ARRECADAÇÃO } \\
\text { DO PIB }\end{array}$ \\
\hline Alteração do ITR & 0,3 a $1,0 \%$ \\
\hline Alteração do IGF & 0,4 a $1,0 \%$ \\
\hline Alteração do IPTU & 0,46 a $0,8 \%$ \\
\hline Alteração do ITCD & 0,05 a 0,49\% \\
\hline Alteração do IPVA & $0,89 \%$ \\
\hline Aplicação do ISS & $0,81 \%$ \\
\hline Diminuição da colisão fiscal do IRPF & $0,7 \%$ \\
\hline Diminuição das renúncias e subsídios fiscais dos impostos & $1,7 \%$ \\
\hline Ampliação da vinculação para a educação (18\% para 20\% na União; & $0,7 \%$ \\
\hline 25\% para 30\% nos Municípios, Estados e DF) & $0,6 \%$ a cada 1 p.p. de \\
\hline Diminuição dos juros da taxa da Selic & $39 \%$ do PIB de 2009 \\
\hline Ampliação das rendas do governo com o Pré-sal & \\
\hline Ipea, 2011 & \\
\hline
\end{tabular}

Fonte: Ipea, 2011

Os dados são bastante esclarecedores, pois a cada imposto se propõe um percentual que poderia alcançar o investimento almejado pela sociedade, de $10 \%$ do PIB. O documento do Ipea indica também outras possibilidades de financiamento, como:

- Captar recursos das agências públicas de fomento nacionais (BNDES, $\mathrm{BNB}$, etc.) através de projetos para todos os níveis e modalidades da 
educação; • Captar recursos de agências internacionais de fomento para realização de obras e outros bens e serviços que o sistema demanda; • Captar recursos de empresas públicas estatais e privadas; - Buscar a parceria com a sociedade como forma de viabilizar programas e ações na área; •Implementar políticas de controle social e fiscalização dos recursos públicos a serem aplicados em educação; • Criar no MEC comissão de acompanhamento e monitoramento das receitas e despesas com educação nos três entes federados (IPEA, 2011).

Neste sentido, somente priorizando de fato a educação pública com investimento público é que se podem melhorar os indicadores nos sistemas de ensino, atendendo a expansão com qualidade, avançando nas condições precárias da educação.E nesta prioridade está a discussão sobre a Reforma Tributária.

O processo histórico da política de financiamento da educação pública brasileira vem se constituindo numa das estratégias do Estado Neoliberal na descentralização da gestão e dos recursos na área educacional, sem ampliação dos recursos que atendam uma expansão da Educação Básica com qualidade. A política de fundos via Fundef e Fundeb, trazem implicações para a não responsabilidade da União com a construção de um Sistema Nacional de Educação, e com o financiamento da Educação Básica, assumindo uma função meramente supletiva e distributiva, reduzindo sua participação na ampliação dos recursos destinados à manutenção do ensino. No entanto, enquanto órgão centralizador, o Estado ainda assume a função de avaliação e controle da gestão dos sistemas de ensino.

Para a melhoria da educação pública brasileira a política de fundos tem suas limitações, pois não representa todos os recursos para a educação, bem como, não amplia os recursos já destinados anteriormente ao Fundef e Fundeb. Faz-se necessário que os diferentes movimentos e organizações em defesa da escola pública realizem o debate e a correlação de forças para que o Estado amplie os recursos destinados à educação, principalmente no aspecto do investimento do PIB, bem como sejam realizadas as reformas necessárias no Estado para atender a melhoria da precarização que se encontram os diferentes níveis de ensino.

\section{Referências}

ARELARO, Lisete Regina Gomes. Financiamento e Qualidade da Educação Brasileira: Algumas reflexões sobre o documento "Balanço do $1^{\circ}$ Ano do FUNDEF - relatório MEC". In: DOURADO, Luis Fernando. (Org.). Financiamento da Educação Básica. Campinas, SP: Autores Associados, 1999, p.27-44.

ARELARO, Lisete Regina Gomes; GIL, I-Juca-Pirama. Política de fundos na educação: duas posições. In: LIMA, Maria José Rocha, DIDONET, Vital. (Org.) FUNDEB - Fundo de Manutenção e Desenvolvimento da Educação Básica e Valorização dos Profissionais da Educação: avanços na universalização da Educação Básica. Brasília: INEP, 2006, p.71-88.

BRASIL. Ministério da Administração e Reforma do Estado (MARE). Plano Diretor da Reforma do Aparelho do Estado - PDRAE. Brasília: MEC, 1995.

BRASIL. Ministério da Educação. Lei Federal n⿳0 9.424, de 24 de dezembro de 1996. Regulamenta o Fundo de Manutenção e Desenvolvimento do Ensino Fundamental e de 
Valorização dos Profissionais do Magistério - FUNDEF. Brasília. Disponível em: <http://www.mec.gov.br/sef/fundef/legisla>. Acesso em: 16 mar. 2010.

Ministério da Educação. Lei Federal no 11.494, de 20 de junho de 2007. Regulamenta o Fundo de Manutenção e Desenvolvimento da Educação Básica e de Valorização dos Profissionais da Educação - FUNDEB. Brasília. Disponível em: <http://www.mec.gov.br/sef/fundef/legisla>. Acesso em: 16 mar. 2010.

. Ministério da Educação. O plano de desenvolvimento da educação: razões, princípios e programas. Brasília: MEC, 2007. . Secretaria de Assuntos Estratégicos da Presidência da República. Financiamento da educação: necessidades e possibilidades. Brasília: IPEA, Documentos do IPEA, n. 124, dez/2011.

CABRAL NETO, Antônio; RODRIGUEZ, Jorge. Reformas Educacionais na América Latina: Cenários, Proposições e Resultados. In: CABRAL NETO, Antônio (Orgs). Pontos e Contrapontos da Política Educacional: Uma Leitura Contextualizada de Iniciativas Governamentais. Brasília, Líber Livro Editora, 2007, p. 13-47.

CURY, Jamil. Estado e políticas de financiamento em educação. Educação e sociedade, Campinas/SP, v. 28, n. 100, p. 831-855, out. 2007.

DAVIES, Nicholas. Financiamento da educação: novos ou velhos desafios? São Paulo: Xamã, 2004.

DAVIES, Nicholas. FUNDEB: a redenção da Educação Básica?Campinas/SP: Autores Associados, 2008.

MARANHÃO. Lei Orçamentária Anual de 2014. Dispõe sobre o orçamento da Prefeitura Municipal de São Luís para 2014. São Luís: 2014a. Disponível em: <www.saoluis.ma. gov.br>. Acesso em: 22 jul., 2014.

Boletim da Setorial da Educação/CSPConlutas. São Luís, v.2, n.2, 2013.

PINTO, José Marcelino de Rezende, ADRIÃO, T. A política recente de fundos para o financiamento da educação e seus efeitos no pacto federativo. Educação e Sociedade, Campinas, v. 28, n. 100, p. 877-897, out. 2007.

PINTO, José Marcelino de Rezende. Um fundinho chamado "fundão". In: DOURADO, Luis Fernando. Financiamento da Educação Básica. Campinas SP: Autores Associados, 1999.

SAVIANI, Dermeval. Da nova LDB ao FUNDEB: por uma outra política educacional. Campinas/SP: Autores Associados, 2008.

SAVIANI, Dermeval. PDE - Plano de Desenvolvimento da Educação: Análise crítica da política do MEC. Campinas/SP: Autores Associados, 2009.

TEIXEIRA, Anisio. Educação é direito. Rio de Janeiro: Editora da UFRJ, 1996. 


\footnotetext{
${ }^{1}$ Coordenadora Pedagógica da rede pública municipal e estadual; militante da Setorial da Educação da Central Sindical e Popular Coordenação Nacional de Lutas (CSPConlutas)
}

${ }^{2}$ Os estudos contidos neste artigo estão inseridos na pesquisa da Dissertação "O Financiamento da Educação Básica: avanços e limites na Política de Valorização do Magistério da Rede Pública Municipal de São Luís MA (2007-2013)", do Mestrado em Educação, do Programa de Pós-Graduação em Educação, da Universidade Federal do Maranhão.

${ }^{3}$ A Campanha Nacional dos $10 \%$ do PIB para a Educação Pública Já, foi organizada em 2011 mediante a realização de um Plebiscito de Consulta Popular sobre a ampliação dos investimentos na educação pública, no sentido de tensionar o governo a incluir imediatamente a meta no PNE em debate, a aplicação de $10 \%$ do PIB no primeiro ano de vigência do Plano. A Campanha teve inicialmente o apoio de diferentes entidades como Andes-SN, Anel, CSP-Colutas, Movimento Sem Terra (MST), Sinasefe, Sindsprev e outras.

${ }^{4}$ A categoria do Magistério é utilizada conforme definida na Lei de Diretrizes e Bases da Educação Nacional (LDB), $\mathrm{n}^{\circ}$ 9.394/96, envolvendo os profissionais que atuam nas atividades de ensino: professores da Educação Básica, orientadores, supervisores e gestores escolares; Magistério também é utilizada pelo Fundeb.

${ }^{5}$ O Siope é um sistema eletrônico, operacionalizado pelo Fundo Nacional de Desenvolvimento da Educação (FNDE), instituído para coleta, processamento, disseminação e acesso público às informações referentes aos orçamentos de educação da União, dos Estados, do Distrito Federal e dos Municípios.

${ }^{6}$ Os recursos destinados para a MDE são compostos pelos recursos: do Fundeb; do salário educação; e por outros recursos para a MDE. Os recursos do Fundeb equivalem a apenas 56\% da totalidade dos recursos destinados à educação pública municipal em 2014 (MARANHÃO, 2014).

${ }^{7}$ No século XXI foram criados vários portais de divulgação dos recursos recebidos e gastos pelos poderes públicos, estimulando a transparência pública como: o Siope; Banco do Brasil; Tribunal de Contas; A nível de Fundeb foi criado o Conselho de Acompanhamento, Controle Social e Fiscalização de Recursos, com participação das diferentes representações: Poder Executivo Municipal, Semed, professores, diretores de escola, servidores técnico-administrativos, pais de alunos e estudantes.

${ }^{8}$ Os impostos a serem alterados são: Imposto Territorial Rural (ITR); Imposto de Grandes Fortunas (IGV); Imposto Predial e Territorial Urbano (IPTU); Imposto sobre a Transmissão de Bens ou Direitos (ITCD); Imposto sobre a Propriedade de Veículos Automotivos (IPVA); Imposto Sobre Serviço (ISS); Imposto de Renda de Pessoa Física (IRPF).

Recebido: $\quad$ jun/2015 $\quad$ Aprovado: jul/2015 